\title{
Rescue Procedures after Suboptimal Deep Brain Stimulation Outcomes in Common Movement Disorders
}

\author{
Adam M. Nagy and Christopher M. Tolleson * \\ Department of Neurology, Vanderbilt University Medical Center, 1161 21st Avenue South, \\ A-0118 Medical Center North, Nashville, TN 37232, USA; adam.nagy@vanderbilt.edu \\ * Correspondence: christopher.tolleson@vanderbilt.edu; Tel.: +1-615-936-2025; Fax: +1-615-936-1229
}

Academic Editors: Tipu Aziz and Alex Green

Received: 3 July 2016; Accepted: 28 September 2016; Published: 8 October 2016

\begin{abstract}
Deep brain stimulation (DBS) is a unique, functional neurosurgical therapy indicated for medication refractory movement disorders as well as some psychiatric diseases. Multicontact electrodes are placed in "deep" structures within the brain with targets varying depending on the surgical indication. An implanted programmable pulse generator supplies the electrodes with a chronic, high frequency electrical current that clinically mimics the effects of ablative lesioning techniques. DBS's efficacy has been well established for its movement disorder indications (Parkinson's disease, essential tremor, and dystonia). However, clinical outcomes are sometimes suboptimal, even in the absence of common, potentially reversible complications such as hardware complications, infection, poor electrode placement, and poor programming parameters. This review highlights some of the rescue procedures that have been explored in suboptimal DBS cases for Parkinson's disease, essential tremor, and dystonia. To date, the data is limited and difficult to generalize, but a large majority of published reports demonstrate positive results. The decision to proceed with such treatments should be made on a case by case basis. Larger studies are needed to clearly establish the benefit of rescue procedures and to establish for which patient populations they may be most appropriate.
\end{abstract}

Keywords: Parkinson's disease; essential tremor; dystonia; deep brain stimulation; treatment failure; rescue leads

\section{Introduction}

Deep brain stimulation (DBS) is a unique and exciting functional neurosurgical therapy, allowing for easily adjustable post-surgical changes to an implanted programmable device, which maximizes long-term clinical outcomes. It involves neurosurgical implantation of multicontact electrodes either unilaterally or bilaterally in specific anatomical areas "deep" within the brain. Targets vary depending on the indication for surgery. These electrodes are connected by a tunneled extension wire to a pulse generator, or neurostimulator, typically implanted in a subcutaneous pocket below the clavicle. The neurostimulator provides a modifiable, high frequency electrical current that modulates the neurocircuitry surrounding the electrodes, clinically mimicking the effects of ablative stereotactic lesioning techniques [1,2]. The stimulation parameters (amplitude, pulse width and frequency) as well as activated contact(s) can be easily adjusted by the treating physician in the clinic. Depending on the comfort level of the physician, patients can also be given varying levels of control over their programming settings. DBS has Food and Drug Administration (FDA) approval in two conditions, Parkinson's disease (PD) and essential tremor (ET). DBS also has a humanitarian device exemption for dystonia and obsessive compulsive disorder. Outside of these approved indications, DBS has been used for a variety of conditions including Parkinson's plus disorders, Huntington's disease, 
Tourette's, Alzheimer's, epilepsy, chronic pain, major depression, post-traumatic stress disorder, and schizophrenia among others [3]. In general, DBS is indicated in all its approved conditions when prospective patients are symptomatically severe and refractory to medical treatment, or when medication adverse effects become intolerable [4].

The process of selecting proper candidates for DBS, successfully implanting the electrode(s) in the proper location, and appropriately programming the DBS device is complex. When done correctly, the efficacy of DBS is well established [5-8]. However, in some instances, even under optimal circumstances with a multidisciplinary team approach, DBS can lead to suboptimal results either immediately after the initial surgery or, later, as symptom benefit declines [9-11]. When common and reversible complications such as hardware issues, improper lead positioning and inadequate programming are ruled out, the patient and clinicians are left with the difficult decision of what to do next. DBS centers have trialed various options including the use of additional or "rescue" DBS lead(s), moving the established lead to another location, or subsequently using lesioning therapy. Given a paucity of data, it can be difficult for centers to make decisions. It can also be difficult to counsel patients and their families as outcomes are not clear. Obtaining consent and appropriately detailing out risks and benefits in such situations comes with inherent difficulties and should be given careful attention by the DBS team $[12,13]$. This review will highlight the available data on some of the techniques used after suboptimal DBS results in PD, ET, and dystonia patients.

\section{Parkinson's Disease}

Parkinson's disease (PD) is a neurodegenerative disorder characterized by the progressive loss of dopaminergic neurons and the buildup of intracellular inclusions called Lewy bodies composed of alpha synuclein. Clinically, it manifests as both the diagnostic motor features (tremor, bradykinesia, rigidity, and postural instability) as well as a myriad of non-motor features (autonomic instability, neuropsychiatric decline, sleep disorders, pain, etc.). PD medications primarily involve modulation of the dopaminergic pathway and target motor features, whereas non-motor features are much more difficult to treat.

DBS is a proven adjunctive surgical therapy for treatment of the motor symptoms of PD [6,14,15]. It is currently approved for levodopa-responsive PD patients with at least 4 years of disease not adequately controlled with medication or whose treatment is complicated by medication-related side effects (i.e., motor fluctuations, dyskinesias). The surgery has been approved for PD since 2002 with recent indications suggesting that earlier usage in the disease may be effective [16]. Compared to best medical therapy alone, DBS in conjunction with medication has been proven far superior. Studies have demonstrated a notable improvement in quality of life, motor scores, and a reduction of wearing off in patients who have received DBS [17-19]. Overall benefits have been maintained for up to 11 years according to long-term follow-up studies [20-22] although there is some concern that any initial benefit in gait or posture may deteriorate more quickly [23].

The most commonly used targets are the subthalamic nucleus (STN) and globus pallidus internus (GPi). Large comparative trials have demonstrated equal benefit in regards to the overall treatment of PD motor symptoms between targets [6,24]. However, there were subtle differences identified, which are still continuously being explored. For example, STN stimulation classically has allowed for greater medication reduction post-surgery, and GPi stimulation has seemed more advantageous for patients with depression, greater balance difficulty, and impairments in verbal fluency [6,24,25]. The longest follow-up in the large trials directly comparing the two targets was 24 months [6,24]. There is still no unifying consensus on specific criteria for favoring one target over the other with the current data. Different DBS centers still differ on their approaches for target selection and often will use the target with which they have the most experience and comfort.

DBS in these two targets can be said to have "failed" for many reasons. Some of the more common reasons include improper patient selection, suboptimal electrode placement, suboptimal management (programming and medications), hardware complications (infection, lead fracture, dead 
battery), and progression of PD such that symptoms not modified by DBS become the patient's primary disability [11]. Exclusive of these more common reasons for failure of PD DBS, patients can still have inadequate or progressively lessening motor benefit despite good lead positioning and programming parameters $[10,11]$. This can manifest as reemergence of dystonia, worsening in motor fluctuations and dyskinesias, and progression in the cardinal motor symptoms (tremor, bradykinesia, rigidity) initially modified by DBS $[10,11]$. In certain patients, up titration of dopaminergics in attempts to adequately control breakthrough symptoms can also lead to disabling side effects (neuropsychiatric changes, fatigue, sleep disruption, impulse control disorders, orthostatic hypotension, and dyskinesia among others). Case studies and series have reported using additional leads in the other primary PD DBS target (i.e., STN stimulation to rescue failed GPi stimulation and vice versa) in these circumstances with some success [15,26-30].

Published cases where patients underwent GPi stimulation for failed STN stimulation generally report patients with a young age of disease onset (average age 41) and a long interval of success with their initial STN surgery (average of 8 years until rescue surgery) $[26,27,29,30]$. In all reviewed cases, the reason for failure was disabling dyskinesia or dystonia. Discontinuation of STN stimulation after initiation of GPi stimulation sometimes led to worse control of cardinal motor features, leading to continued STN stimulation in four of seven cases reviewed [26,27,29,30]. Of the seven cases, six achieved a clinically significant benefit with the addition of GPi stimulation [26,27,29,30]. Benefits included reduction in the dystonia, dyskinesia, and levodopa equivalent daily dose (i.e., total medication needed) $[26,27,29,30]$.

In the six cases reviewed where STN stimulation was used to rescue failed GPi stimulation, the reason for failure was worsening motor symptoms soon after surgery (within the first 2-3 years) [15,28]. Average age at disease onset was also in the 40s (exact ages at onset unavailable from one study). Notably, in three of the six cases, there were hardware complications that necessitated the removal of at least one GPi electrode prior to the use of rescue leads [15,28]. In all cases, STN stimulation replaced GPi stimulation, rather than stimulation of both regions, as the GPi leads were already removed in all patients $[15,28]$. STN stimulation led to improved United Parkinson's disease Rating Scale Part III (UPDRS-III) scores, decreased levodopa daily dose, and cessation of or improvement in dyskinesia $[15,28]$.

Another interesting rescue procedure reported by Deligny et al. was that of a bilateral subthalamotomy performed through DBS electrodes prior to their removal due to hardware infection [31]. In this case, radiofrequency subthalamotomy through the leads led to a durable benefit in measured motor scores, dyskinesia and off times [31]. Unfortunately, after the procedure, there were some mild cognitive and motivation side effects witnessed as well [31].

Finally, other targets besides the STN and GPi have been explored in PD DBS such as the pedunculopontine nucleus (PPN). This target has primarily been used for PD patients suffering from freezing of gait (FOG) and other gait disturbances, either as the sole target or in combination with STN DBS. It has the potential to be used as a rescue target in the future but further study is needed. The PPN was initially chosen as a potential DBS target given work in animal models which has shown the PPN plays a significant role in the normal operation of axial muscles which help regulate posture and gait [32-34]. FOG is a disabling symptom commonly seen in PD where patients literally "freeze" to the floor when they attempt to ambulate. It commonly occurs with the initiation of gait, with turning or when maneuvering in tight spaces such as doorways and crowds [35,36]. FOG is generally refractory to medications and STN/GPi DBS [37]. Several studies were reviewed that looked at the PPN as the sole target in PD patients with postural instability and gait symptoms (PIGD). A recent meta-analysis was performed on 10 such studies [37]. While there was a statistically significant improvement in motor symptoms and postural instability, the meta-analysis did not find a significant improvement in FOG [37]. The improvement in motor symptoms was also less substantial with PPN stimulation than has been found with STN or GPi stimulation [37]. In contrast, an interesting study by Stefani et al. looked at six PD patients with axial signs simultaneously implanted in the PPN and STN [38]. Patients 
were analyzed 2-6 months after surgery in ON/OFF medication states with either or both targets activated. The PPN was particularly effective for gait and posture, and the combination of the targets being "on" was superior to one alone [38]. Liu et al. also report a case of a PD patient with FOG implanted simultaneously with bilateral PPN and STN leads [39]. The investigators did not test the leads in both targets simultaneously due to problems with dizziness when all leads were activated. However, on testing individual targets, sole stimulation of the PPN leads did show some benefit in the gait problems whereas the STN leads did not [39].

In summary, case reports of rescue procedures for PD have been generally positive, though follow-up has been short. Typically, rescue procedures have involved stimulation of the approved target that was not originally implanted (i.e., STN for failed GPi or vice versa). Subthalamotomy performed through existing DBS electrodes has also been attempted. Rescue procedures seem to be more common in those with a young age of disease onset. Stimulation of the PPN is also an intriguing idea both as an initial therapy and a rescue therapy for those with more axial symptoms and FOG, but currently further study is still needed.

\section{Essential Tremor}

Essential tremor (ET) is the most commonly seen movement disorder [40]. Clinically, it typically manifests as a bilateral action and postural tremor. The disease commonly runs in families, suggesting a hereditary component, yet a specific genetic cause has not been identified [40]. Common therapeutic medications include primidone, beta blockers, topiramate and gabapentin.

DBS is a proven surgical option for medication refractory ET. The accepted target is the ventral intermediate (VIM) nucleus of the thalamus. Unilateral DBS for ET received FDA approval in 1997 although it is commonly used bilaterally. Response to stimulation is often robust, with studies demonstrating $>80 \%$ tremor improvement $[7,8]$. Studies have also demonstrated that this benefit can be persistent over a long period of time (>12 years) [41-43].

In some cases, however, the benefits of DBS either are suboptimal or diminish irrespective of inaccurate lead placement, hardware complications or other device issues [11,44]. Possible reasons for diminishing response include disease progression and tolerance to stimulation. Several different rescue techniques have been attempted to improve tremor control in these patients. Some DBS centers have attempted to either add additional leads or reposition in a second target. These other targets have primarily included the STN, caudal zona inserta (cZI), or the ventralis oralis anterior nucleus of the thalamus (VOA) $[9,45,46]$. Many of these newer targets were selected to see if stimulation of the subthalamic areas (STN, cZI, prelemniscal radiations) would produce similar results to previously used lesioning approaches. Subthalamotomy has been an efficacious surgical option for tremor dating back to the 1960s [47-49]. Our institution has also tried adding a second thalamic lead anterior to the VIM, using the combination of the VOA and VIM leads together to direct current away from structures causing stimulation-induced side effects and allow for more aggressive stimulation parameters [50-52].

In a case series by Blomstedt et al., patients who had failed VIM stimulation underwent re-implantation in the cZI [9]. In this series, they reported a 57\% improvement in tremor control with cZI stimulation, compared to a $25 \%$ improvement in tremor control with prior VIM stimulation [9]. Within their cohort $(n=5)$, however, two of the patients had relatively immediate failure of their VIM leads ( $<6$ months) [9]. This may suggest an initial improper positioning of the leads as opposed to true superiority of the cZI over VIM. The other three patients received their cZI lead implantation an average of 9 years after VIM implantation with benefit [9].

In two series by Mehanna et al. and Oyama et al., a total of seven patients underwent a second operation into the VOA, STN, or prelemniscal radiations for failed VIM stimulation [45,46]. Six of the seven patients had mild to moderate improvement after reoperation $[45,46]$. In some patients, the physicians used simultaneous stimulation of both the new target and VIM, while others had stimulation of the new target alone $[45,46]$. A shortcoming of these series is the heterogeneity of the patient population and treatment strategies. Four of the seven patients did not have ET $[45,46]$. Rather, 
two had multiple sclerosis induced tremor, one had tremor from a treated thalamic anteriovenous malformation and one had an atypical tremor of unknown cause $[45,46]$. In the three patients with ET, one had maximal tremor control with the VOA rescue lead stimulated alone. The other two had maximal tremor control with simultaneous stimulation of VIM and the new target (one in the VOA and one in the prelemniscal radiations). The varying treatment strategies (different targets and different combinations of stimulation) make this data difficult to interpret.

Yu et al., Isaacs et al. and Sukul et al. from our institution [50-52] published a series in which they used the placement of a second electrode in the thalamus antero-medially to the VIM to direct stimulation away from structures causing stimulation-induced side effects (such as the internal capsule and ventralis caudalis nucleus of the thalamus) [50-52]. Limiting side effects from the initial lead included severe paresthesias, diplopia, dysarthria, and dizziness. The leads were connected in parallel to a common voltage source allowing more control over the field of stimulation [50-52]. Directing the stimulation away from unintended targets allowed for more aggressive stimulation parameters with essentially equivalent or better tremor control and reduced side effects in all patients [50-52].

Bahgat et al. retrospectively reviewed seven patients with ET who underwent unilateral thalamotomy as a rescue procedure after failed VIM DBS [53]. Reasons for failure in these patients included intolerable side effects, malpositioned electrodes, and symptom progression [53]. After thalamotomy, six of the seven patients reported symptomatic improvement, though only three of those six reported corresponding functional improvement and one patient reported no improvement at all [53]. However, only one patient had a significant persistent adverse effect in the form of facial numbness from thalamotomy after DBS [53].

In summary, case reports of rescue procedures for ET have also been generally positive, though cohorts have been notably heterogeneous. Several newer targets have been tried in combination with and as a replacement for VIM stimulation, which has raised the possibility of a synergistic effect of stimulating different regions. Thalamotomy for failed DBS had modest success. An alternative rescue approach with favorable results has been implanting additional thalamic leads to direct stimulation away from structures responsible for intolerable side effects.

\section{Dystonia}

Dystonia is an unusual movement disorder characterized by sustained and repetitive muscle contraction, often resulting in abnormal posturing [54]. The exact pathophysiology is not known, but the origin appears to be in the basal ganglia. Dystonia can be from a variety of causes such as genetic abnormalities, neurodegenerative conditions, structural changes or insults to the brain, chemical exposures, or medications among others [55,56]. It also has a varied clinical presentation, presenting either as a focal dystonia (i.e., isolated to one body part) versus a more generalized or segmental dystonia $[55,56]$. Common non-surgical treatments for dystonia include botulinum toxin injections, anticholinergic medications, and benzodiazepines.

DBS is a proven surgical treatment for dystonia refractory to medication and botulinum toxin injections, particularly primary generalized dystonia (i.e., genetic or idiopathic) [5]. This treatment received Humanitarian Device Exemption from the FDA in 2003. The primary target has been the GPi in the majority of cases due to prior experience with lesioning therapies and the use of the target in the PD population [57]. More recent DBS cases have used the STN target as well, most commonly with focal cervical dystonia [5,58]. Some studies report up to a $60 \%-70 \%$ improvement on dystonia rating scales in generalized dystonia post GPi DBS [5,58-61]. Results in focal dystonias are more variable. The most common dystonia, cervical dystonia, does tend to have good response post DBS [62-64]. The responses to DBS in other types of focal or segmental dystonia are less well defined and reported less in the literature [5]. Post-surgical programming in this population can also often be challenging compared to PD and ET. Unlike these movement disorders where stimulation results in immediate clinical results, there is a long latency between programming adjustments and resulting clinical benefit that can be months in duration. 
Like the other movement disorders already discussed, dystonia patients can have a suboptimal response to DBS despite good lead positioning and a lack of detectable reversible complications such as hardware malfunction or poor programming parameters [46,65]. Various techniques have been applied in the dystonia population. A case series by Oyama et al. reported two patients who underwent rescue lead placement for dystonia [46]. The first was a patient with cervical dystonia who had incomplete benefit from bilateral GPi stimulation and underwent implantation of a second rescue lead into the left GPi [46]. The rationale was that the patient's original left GPi lead was $2.4 \mathrm{~mm}$ more anterior than the right on repeat imaging. The second was a tardive dyskinesia/dystonia patient who had incomplete benefit from bilateral GPi stimulation and underwent implantation of bilateral STN rescue leads two years later [46]. Both patients had complete symptom resolution with stimulation of both the original and rescue leads [46]. In the first case, the authors stimulated all contacts immediately after the addition of the third lead with excellent results. In the second case, the authors attempted to reduce GPi stimulation in favor of purely STN stimulation but only with activation of all four leads did the patient achieve maximum benefit. Benefit was sustained at 17 months for the left GPi rescue operation and 15 months for the bilateral STN rescue procedure at the time of publication [46].

No other case series were found that specifically addressed rescue leads for suboptimal DBS results in dystonia. There was one report where bilateral STN DBS was used as a rescue procedure for a failed unilateral pallidotomy [65]. Also, Schjerling et al. did perform a study directly comparing the STN to the GPi as targets for dystonia [66]. Part of the study did address simultaneous stimulation of the two targets. The study was a randomized, double-blind crossover study, and all patients received both STN and GPi leads [66]. The study included 13 patients and was quite heterogeneous; ages ranged from 12 to 57 years, disease duration ranged from 3 to 30 years, and it was roughly half generalized and half focal dystonia [66]. While the results did not demonstrate a statistically significant difference between GPi and STN stimulation, there was a trend toward greatest improvement with simultaneous stimulation of both targets, followed by STN alone and then GPi alone [66]. As with the single case report mentioned above, there may be a role for simultaneous stimulation of the STN and GPi targets in patients who have failed to achieve beneficial results with a single target.

In summary, there is little available data regarding rescue lead implantation for dystonia patients. In the one case report reviewed in addition to the study employing simultaneous GPi and STN stimulation, the increased benefit of combined STN and GPi stimulation is intriguing and could be looked at more intensely in additional studies with larger populations. The published number of cases is currently extremely limited. Studies of DBS in dystonia are complicated by the variety of clinical presentations and underlying causes of dystonia. Studies are also complicated by the delay in benefit from stimulation which can take several months to manifest, if not longer. This makes programming inherently difficult as well as determining what qualifies as a DBS failure.

\section{Discussion and Conclusions}

As described, published rescue procedures for failed DBS in PD, ET, and dystonia have been performed with generally positive reported results and do have a role in cases of suboptimal DBS outcomes. However, the data is still quite difficult to apply to any general population for several reasons. There is a high degree of individualization that takes place between institutions and patients when it comes to such procedures. The amount of data is still very limited, and is currently entirely in the form of case reports and series. Further, there is little incentive to write or publish case reports of negative outcomes after rescue procedures, likely creating significant publication bias.

Ultimately, more established guidelines, utilizing more concrete data, are needed for performing rescue therapies in suboptimal DBS outcomes in each of the indications discussed. However, a consensus set of guidelines based on better data from prospective blinded, randomized clinical trials may be difficult to achieve given the ethics of performing a blinded randomized trial of a rescue surgical therapy as well as the multiple differing variables present in situations where rescue leads are required. Nonetheless, with the uncertainty of the current data and the difficulty of putting a patient through 
another surgery with poorly established outcomes, it is a given that rescue procedures should only be performed as a last resort, after every attempt to optimize the current DBS lead has been undertaken. Postoperative imaging should be performed to verify proper lead placement, hardware checked to make sure its functioning appropriately, medications optimized to the fullest, and programming adjustments exhausted as much as possible. There should be multidisciplinary discussions between experienced DBS neurologists and neurosurgeons before undertaking these procedures where targets and procedural options are discussed and weighed. The risks, ethics, and potential emotional distress of putting patients and their families through another brain surgery should never be taken lightly.

This review summarizes the available data on rescue therapies post DBS. More information and experience from DBS centers, both good and bad, is needed to better establish future guidelines and techniques. Still, available data does suggest that some patients can achieve benefits with rescue procedures. The decision to proceed with such treatment should be undertaken with caution and involve open discussions with a team of DBS physicians, patients and their families, fully explaining the uncertainty of results.

Author Contributions: A.N. and C.T. both contributed to the conception of the review topic, and shared in the writing of this manuscript. A.N. was the primary writer with C.T. providing guidance and editing.

Conflicts of Interest: A.N. declares no conflict of interest. C.T. has done consulting for Medtronic, Acadia and Teva. The mentioned entities had no role in the topics of the invited review; in the writing of the manuscript, and in the decision to publish.

\section{References}

1. Volkmann, J.; Herzog, J.; Kopper, F.; Deuschl, G. Introduction to the programming of deep brain stimulators. Mov. Disord. 2002, 17, S181-S187. [CrossRef] [PubMed]

2. Volkmann, J. Surgery for Parkinson's disease. In Therapeutics of Parkinson's Disease and Other Movement Disorders; Hallet, M., Poewe, W., Eds.; John Wiley and Sons: Chichester, UK, 2008; pp. 121-136.

3. Ostergard, T.; Miller, J.P. Deep brain stimulation: New directions. J. Neurosurg. Sci. 2014, 58, $191-198$. [PubMed]

4. Siddiqui, M.S.; Haq, I.U.; Okun, M.S. Deep brain stimulation in movement disorders. CONTINUUM Lifelong Learn. Neurol. 2010, 16, 110-130. [CrossRef] [PubMed]

5. Crowell, J.L.; Shah, B.B. Surgery for dystonia and tremor. Curr. Neurol. Neurosci. Rep. 2016, 16, 1-13. [CrossRef] [PubMed]

6. $\quad$ Follett, K.A.; Weaver, F.M.; Stern, M.; Hur, K.; Harris, C.L.; Luo, P.; Marks, W.J., Jr.; Rothlind, J.; Sagher, O.; Moy, C.; et al. Pallidal versus subthalamic deep-brain stimulation for Parkinson's disease. N. Engl. J. Med. 2010, 362, 2077-2091. [CrossRef] [PubMed]

7. Nazzaro, J.M.; Pahwa, R.; Lyons, K.E. Long-term benefits in quality of life after unilateral thalamic deep brain stimulation for essential tremor: Clinical article. J. Neurosurg. 2012, 117, 156-161. [CrossRef] [PubMed]

8. Ondo, W.; Jankovic, J.; Schwartz, K.; Almaguer, M.; Simpson, R.K. Unilateral thalamic deep brain stimulation for refractory essential tremor and Parkinson's disease tremor. Neurology 1998, 51, 1063-1069. [CrossRef] [PubMed]

9. Blomstedt, P.; Lindvall, P.; Linder, J.; Olivecrona, M.; Forsgren, L.; Hariz, M.I. Reoperation after failed deep brain stimulation for essential tremor. World Neurosurg. 2012, 78, e1-e5. [CrossRef] [PubMed]

10. Granziera, C.; Pollo, C.; Russmann, H.; Staedler, C.; Ghika, J.; Villemure, J.G.; Burkhard, P.R.; Vingerhoets, F.J.G. Sub-acute delayed failure of subthalamic DBS in Parkinson's disease: The role of micro-lesion effect. Parkinsonism Relat. Disord. 2008, 14, 109-113. [CrossRef] [PubMed]

11. Okun, M.S.; Tagliati, M.; Pourfar, M.; Fernandez, H.H.; Rodriguez, R.L.; Alterman, R.L.; Foote, K.D. Management of referred deep brain stimulation failures: A retrospective analysis from 2 movement disorders centers. Arch. Neurol. 2005, 62, 1250-1255. [CrossRef] [PubMed]

12. Gilbert, F. Self-estrangement and deep brain stimulation: Ethical issues related to forced explantation. Neuroethics 2014, 8, 107-114. [CrossRef]

13. Unterrainer, M.; Oduncu, F.S. The ethics of deep brain stimulation (DBS). Med. Health Care Philos. 2015, 18, 475-485. [CrossRef] [PubMed] 
14. Kleiner-Fisman, G.; Herzog, J.; Fisman, D.N.; Tamma, F.; Lyons, K.E.; Pahwa, R.; Lang, A.E.; Deuschl, G. Subthalamic nucleus deep brain stimulation: Summary and meta-analysis of outcomes. Mov. Disord. 2006, 21, S290-S304. [CrossRef] [PubMed]

15. Volkmann, J.; Allert, N.; Voges, J.; Sturm, V.; Schnitzler, A.; Freund, H.J. Long term results of bilateral pallidal stimulation in Parkinson's disease. Ann. Neurol. 2004, 55, 871-875. [CrossRef] [PubMed]

16. Schuepbach, W.M.M.; Rau, J.; Knudsen, K.; Volkmann, J.; Krack, P.; Timmermann, L.; Hälbig, T.D.; Hesekamp, H.; Navarro, S.M.; Meier, N.; et al. Neurostimulation for Parkinson's disease with early motor complications. N. Engl. J. Med. 2013, 368, 610-622. [CrossRef] [PubMed]

17. Sharma, A.; Szeto, K.; Desilets, A.R. Efficacy and safety of deep brain stimulation as an adjunct to pharmacotherapy for the treatment of Parkinson disease. Ann. Pharmacother. 2012, 46, 248-254. [CrossRef] [PubMed]

18. Weaver, F.M.; Follett, K.; Stern, M.; Hur, K.; Harris, C.; Marks, W.J.; Rothlind, J.; Sagher, O.; Reda, D.; Moy, C.S.; et al. Bilateral deep brain stimulation vs. best medical therapy for patients with advanced Parkinson disease: A randomized controlled trial. JAMA 2009, 301, 63-73. [CrossRef] [PubMed]

19. Williams, A.; Gill, S.; Varma, T.; Jenkinson, C.; Quinn, N.; Mitchell, R.; Scott, R.; Ives, N.; Rick, C.; Daniels, J.; et al. Deep brain stimulation plus best medical therapy versus best medical therapy alone for advanced Parkinson's disease (PD SURG trial): A randomised, open-label trial. Lancet Neurol. 2010, 9, 581-591. [CrossRef]

20. Castrioto, A.; Lozano, A.M.; Poon, Y.Y.; Lang, A.E.; Fallis, M.; Moro, E. Ten-year outcome of subthalamic stimulation in Parkinson disease: A blinded evaluation. Arch. Neurol. 2011, 68, 1550-1556. [CrossRef] [PubMed]

21. Rizzone, M.G.; Fasano, A.; Daniele, A.; Zibetti, M.; Merola, A.; Rizzi, L.; Piano, C.; Piccininni, C.; Romito, L.M.; Lopiano, L.; et al. Long-term outcome of subthalamic nucleus DBS in Parkinson's disease: From the advanced phase towards the late stage of the disease? Parkinsonism Relat. Disord. 2014, 20, 376-381. [CrossRef] [PubMed]

22. Zibetti, M.; Merola, A.; Rizzi, L.; Ricchi, V.; Angrisano, S.; Azzaro, C.; Artusi, C.A.; Arduino, N.; Marchisio, A.; Lanotte, M.; et al. Beyond nine years of continuous subthalamic nucleus deep brain stimulation in Parkinson's disease. Mov. Disord. 2011, 26, 2327-3234. [CrossRef] [PubMed]

23. George, R.S.; Nutt, J.G.; Burchiel, K.J.; Horak, F.B. A meta-regression of the long-term effects of deep brain stimulation on balance and gait in PD. Neurology 2010, 75, 1292-1299. [CrossRef] [PubMed]

24. Liu, Y.; Li, W.; Tan, C.; Liu, X.; Wang, X.; Gui, Y.; Qin, L.; Deng, F.; Hu, C.; Chen, L. Meta-analysis comparing deep brain stimulation of the globus pallidus and subthalamic nucleus to treat advanced Parkinson disease: A review. J. Neurosurg. 2014, 121, 709-718. [CrossRef] [PubMed]

25. Martinez-Ramirez, D.; Hu, W.; Bona, A.R.; Okun, M.S.; Wagle Shukla, A. Update on deep brain stimulation in Parkinson's disease. Transl. Neurodegener. 2015, 4, 12. [CrossRef] [PubMed]

26. Allert, N.; Schnitzler, A.; Sturm, V.; Maarouf, M. Failure of long-term subthalamic nucleus stimulation corrected by additional pallidal stimulation in a patient with Parkinson's disease. J. Neurol. 2012, 259, 1244-1246. [CrossRef] [PubMed]

27. Cook, R.J.; Jones, L.; Fracchia, G.; Anderson, N.; Miu, J.; Meagher, L.J.; Silburn, P.A.; Silberstein, P. Globus pallidus internus deep brain stimulation as rescue therapy for refractory dyskinesias following effective subthalamic nucleus stimulation. Stereotact. Funct. Neurosurg. 2015, 93, 25-29. [CrossRef] [PubMed]

28. Houeto, J.L.; Bejjani, P.B.; Damier, P.; Staedler, C.; Bonnet, A.M.; Pidoux, B.; Dormont, D.; Cornu, P.; Agid, Y. Failure of long-term pallidal stimulation corrected by subthalamic stimulation in PD. Neurology 2000, 55, 728-730. [CrossRef] [PubMed]

29. Matias, C.M.; Silva, D.; Machado, A.G.; Cooper, S.E. "Rescue” of bilateral subthalamic stimulation by bilateral pallidal stimulation: Case report. J. Neurosurg. 2016, 124, 417-421. [CrossRef] [PubMed]

30. Minafra, B.; Fasano, A.; Pozzi, N.G.; Zangaglia, R.; Servello, D.; Pacchetti, C. Eight-years failure of subthalamic stimulation rescued by globus pallidus implant. Brain Stimul. 2014, 7, 179-181. [CrossRef] [PubMed]

31. Deligny, C.; Drapier, S.; Verin, M.; Lajat, Y.; Raoul, S.; Damier, P. Bilateral subthalamotomy through dbs electrodes: A rescue option for device-related infection. Neurology 2009, 73, 1243-1244. [CrossRef] [PubMed] 
32. Ferraye, M.U.; Debû, B.; Fraix, V.; Goetz, L.; Ardouin, C.; Yelnik, J.; Henry-Lagrange, C.; Seigneuret, E.; Piallat, B.; Krack, P.; et al. Effects of pedunculopontine nucleus area stimulation on gait disorders in Parkinson's disease. Brain 2010, 133, 205-214. [CrossRef] [PubMed]

33. Stein, J.F. Akinesia, motor oscillations and the pedunculopontine nucleus in rats and men. Exp. Neurol. 2009, 215, 1-4. [CrossRef] [PubMed]

34. Mazzone, P.; Lozano, A.; Stanzione, P.; Galati, S.; Scarnati, E.; Peppe, A.; Stefani, A. Implantation of human pedunculopontine nucleus: A safe and clinically relevant target in Parkinson's disease. Neuroreport 2005, 16, 1877-1881. [CrossRef] [PubMed]

35. Morris, M.E.; Iansek, R.; Galna, B. Gait festination and freezing in Parkinson's disease: Pathogenesis and rehabilitation. Mov. Disord. 2008, 23, S451-S460. [CrossRef] [PubMed]

36. Vercruysse, S.; Spildooren, J.; Heremans, E.; Vandenbossche, J.; Levin, O.; Wenderoth, N.; Swinnen, S.P.; Janssens, L.; Vandenberghe, W.; et al. Freezing in Parkinson's disease: A spatiotemporal motor disorder beyond gait. Mov. Disord. 2012, 27, 254-263. [CrossRef] [PubMed]

37. Golestanirad, L.; Elahi, B.; Graham, S.J.; Das, S.; Wald, L.L. Efficacy and safety of pedunculopontine nuclei (PPN) deep brain stimulation in the treatment of gait disorders: A meta-analysis of clinical studies. Can. J. Neurol. Sci. 2016, 43, 120-126. [CrossRef] [PubMed]

38. Stefani, A.; Lozano, A.M.; Peppe, A.; Stanzione, P.; Galati, S.; Tropepi, D.; Pierantozzi, M.; Brusa, L.; Scarnati, E.; Mazzone, P. Bilateral deep brain stimulation of the pedunculopontine and subthalamic nuclei in severe Parkinson's disease. Brain 2007, 130, 1596-1607. [CrossRef] [PubMed]

39. Liu, H.G.; Zhang, K.; Yang, A.C.; Zhang, J.G. Deep brain stimulation of the subthalamic and pedunculopontine nucleus in a patient with Parkinson's disease. J. Korean Neurosurg. Soc. 2015, 57, $303-306$. [CrossRef] [PubMed]

40. Chunling, W.; Zheng, X. Review on clinical update of essential tremor. Neurol. Sci. 2016, 37, 495-502. [CrossRef] [PubMed]

41. Baizabal-Carvallo, J.F.; Kagnoff, M.N.; Jimenez-Shahed, J.; Fekete, R.; Jankovic, J. The safety and efficacy of thalamic deep brain stimulation in essential tremor: 10 years and beyond. J. Neurol. Neurosurg. Psychiatry 2014, 85, 567-572. [CrossRef] [PubMed]

42. Børretzen, M.N.; Bjerknes, S.; Sæhle, T.; Skjelland, M.; Skogseid, I.M.; Toft, M.; Dietrichs, E. Long-term follow-up of thalamic deep brain stimulation for essential tremor-Patient satisfaction and mortality. BMC Neurol. 2014, 14, 120. [CrossRef] [PubMed]

43. Pilitsis, J.G.; Metman, L.V.; Toleikis, J.R.; Hughes, L.E.; Sani, S.B.; Bakay, R.A. Factors involved in long-term efficacy of deep brain stimulation of the thalamus for essential tremor. J. Neurosurg. 2008, 109, 640-646. [CrossRef] [PubMed]

44. Ellis, T.M.; Foote, K.D.; Fernandez, H.H.; Sudhyadhom, A.; Rodriguez, R.L.; Zeilman, P.; Jacobson, C.E., IV; Okun, M.S. Reoperation for suboptimal outcomes after deep brain stimulation surgery. Neurosurgery 2008, 63, 754-761. [CrossRef] [PubMed]

45. Mehanna, R.; Machado, A.G.; Oravivattanakul, S.; Genc, G.; Cooper, S.E. Comparing two deep brain stimulation leads to one in refractory tremor. Cerebellum 2014, 13, 425-432. [CrossRef] [PubMed]

46. Oyama, G.; Foote, K.D.; Hwynn, N.; Jacobson, C.E.; Malaty, I.A.; Rodriguez, R.L.; Zeilman, P.; Okun, M.S. Rescue leads: A salvage technique for selected patients with a suboptimal response to standard DBS therapy. Parkinsonism Relat. Disord. 2011, 17, 451-455. [CrossRef] [PubMed]

47. Mundinger, F. Results of 500 subthalamotomies in the region of the zona incerta. In Third Symposium on Parkinson's Disease; E \& S Livingstone: Edinburgh, UK; London, UK, 1969; pp. 261-265.

48. Velasco, F.; Jiménez, F.; Pérez, M.L.; Carrillo-Ruiz, J.D.; Velasco, A.L.; Ceballos, J.; Velasco, M. Electrical stimulation of the prelemniscal radiation in the treatment of Parkinson's disease: An old target revised with new techniques. Neurosurgery 2001, 49, 293-308. [CrossRef] [PubMed]

49. Wertheimer, P.; Bourret, J.; Lapras, C. Apropos of the treatment of a dyskinesia by stereotaxic leucotomy. Lyon Med. 1960, 92, 885-889. [PubMed]

50. Isaacs, D.; Butler, J.; Sukul, V.; Tolleson, C.; Fang, J.; Phibbs, F.; Hedera, P.; Yu, H.; Konrad, P. Confined thalamic stimulation in refractory essential tremor. Presented at the 20th International Congress of Parkinson's Disease and Movement Disorders, Berlin, Germany, 19-23 June 2016. 
51. Yu, H.; Hedera, P.; Fang, J.; Davis, T.L.; Konrad, P.E. Confined stimulation using dual thalamic deep brain stimulation leads rescues refractory essential tremor: Report of three cases. Stereotact. Funct. Neurosurg. 2009, 87, 309-313. [CrossRef] [PubMed]

52. Sukul, V.; Isaacs, D.A.; Pallavaram, S.; Rodriguez, W.; Butler, J.; Yu, H.; Neimat, J.S.; Konrad, P. Field-steering rescue lead therapy for patients with essential tremor refractory to ventralis intermedius deep brain stimulation. Neurosurgery 2016, 63, 155-156. [CrossRef] [PubMed]

53. Bahgat, D.; Magill, S.T.; Berk, C.; McCartney, S.; Burchiel, K.J. Thalamotomy as a treatment option for tremor after ineffective deep brain stimulation. Stereotact. Funct. Neurosurg. 2012, 91, 18-23. [CrossRef] [PubMed]

54. Albanese, A.; Bhatia, K.; Bressman, S.B.; DeLong, M.R.; Fahn, S.; Fung, V.S.; Hallett, M.; Jankovic, J.; Jinnah, H.A.; Klein, C.; et al. Phenomenology and classification of dystonia: A consensus update. Mov. Disord. 2013, 28, 863-873. [CrossRef] [PubMed]

55. Geyer, H.L.; Bressman, S.B. The diagnosis of dystonia. Lancet Neurol. 2006, 5, 780-790. [CrossRef]

56. Tarsy, D.; Simon, D.K. Dystonia. N. Engl. J. Med. 2006, 355, 818-829. [CrossRef] [PubMed]

57. Vitek, J.L.; DeLong, M.R.; Starr, P.A.; Hariz, M.I.; Metman, L.V. Intraoperative neurophysiology in DBS for dystonia. Mov. Disord. 2011, 26, S31-S36. [CrossRef] [PubMed]

58. Ostrem, J.L.; Starr, P.A. Treatment of dystonia with deep brain stimulation. Neurotherapeutics 2008, 5, 320-330. [CrossRef] [PubMed]

59. Kupsch, A.; Benecke, R.; Müller, J.; Trottenberg, T.; Schneider, G.H.; Poewe, W.; Eisner, W.; Wolters, A.; Müller, J.U.; Deuschl, G.; et al. Pallidal deep-brain stimulation in primary generalized or segmental dystonia. N. Engl. J. Med. 2006, 355, 1978-1990. [CrossRef] [PubMed]

60. Speelman, J.D.; Contarino, M.F.; Schuurman, P.R.; Tijssen, M.A.J.; de Bie, R.M.A. Deep brain stimulation for dystonia: Patient selection and outcomes. Eur. J. Neurol. 2010, 17, 102-106. [CrossRef] [PubMed]

61. Vidailhet, M.; Vercueil, L.; Houeto, J.L.; Krystkowiak, P.; Benabid, A.L.; Cornu, P.; Lagrange, C.; du Tézenas Montcel, S.; Dormont, D.; Grand, S.; et al. Bilateral deep-brain stimulation of the globus pallidus in primary generalized dystonia. N. Engl. J. Med. 2005, 352, 459-467. [CrossRef] [PubMed]

62. Kiss, Z.H.; Doig-Beyaert, K.; Eliasziw, M.; Tsui, J.; Haffenden, A.; Suchowersky, O. The Canadian multicentre study of deep brain stimulation for cervical dystonia. Brain 2007, 130, 2879-2886. [CrossRef] [PubMed]

63. Skogseid, I.M.; Ramm-Pettersen, J.; Volkmann, J.; Kerty, E.; Dietrichs, E.; Røste, G.K. Good long-term efficacy of pallidal stimulation in cervical dystonia: A prospective, observer-blinded study. Eur. J. Neurol. 2012, 19, 610-615. [CrossRef] [PubMed]

64. Walsh, R.A.; Sidiropoulos, C.; Lozano, A.M.; Hodaie, M.; Poon, Y.Y.; Fallis, M.; Moro, E. Bilateral pallidal stimulation in cervical dystonia: Blinded evidence of benefit beyond 5 years. Brain 2013, 136, 761-769. [CrossRef] [PubMed]

65. Novak, K.E.; Nenonene, E.K.; Bernstein, L.P.; Vergenz, S.; Cozzens, J.W.; Rezak, M. Successful bilateral subthalamic nucleus stimulation for segmental dystonia after unilateral pallidotomy. Stereotact. Funct. Neurosurg. 2007, 86, 80-86. [CrossRef] [PubMed]

66. Schjerling, L.; Hjermind, L.E.; Jespersen, B.; Madsen, F.F.; Brennum, J.; Jensen, S.R.; Løkkegaard, A.; Karlsborg, M. A randomized double-blind crossover trial comparing subthalamic and pallidal deep brain stimulation for dystonia: Clinical article. J. Neurosurg. 2013, 119, 1537-1545. [CrossRef] [PubMed]

(C) 2016 by the authors; licensee MDPI, Basel, Switzerland. This article is an open access article distributed under the terms and conditions of the Creative Commons Attribution (CC-BY) license (http://creativecommons.org/licenses/by/4.0/). 